\title{
Incidence of heart failure among diabetic patients with ischemic heart disease: a cohort study
}

\author{
Senbeta Guteta Abdissa ${ }^{1 *}$, Wakgari Deressa ${ }^{2}$ and Amit J. Shah"
}

\begin{abstract}
Background: In population studies of heart failure (HF), diabetes has been shown to be an independent risk factor. However, the evidence evaluating diabetes mellitus (DM) as an independent risk factor in incident HF in patients with ischemic heart disease (IHD) is scarce. Our study aimed to assess the incidence of HF in diabetic IHD patients compared to non-diabetic IHD patients in Ethiopia.

Methods: A retrospective cohort study was conducted among 306 patients with IHD followed-up at Tikur Anbessa Specialized Hospital in Addis Ababa, Ethiopia. The IHD patients who did not have HF at baseline were followed for 24 months beginning from November 30, 2015. We assessed the incidence of HF in patients with diabetic IHD versus the non-diabetic IHD. Cox proportional hazards models were used to assess the association between diabetic IHD and HF after controlling for important covariates. Hypertension was examined as a possible effect modifier as well.
\end{abstract}

Results: The mean age was 56.8 years, $69 \%$ were male, and 31\% were diabetic. During the 24 months follow-up period, 196 (64.1\%) had incident HF. On multivariate Cox regression, DM was significantly associated with incident HF [Hazard Ratio $=2.04,95 \%$ confidence interval $(C \mathrm{Cl}): 1.32-3.14, p=0.001]$. Furthermore, when the patients were stratified by hypertension (HTN), DM was associated with worse prognosis, the strongest association being in those with co-existing DM and HTN $[\mathrm{HR}=2.57,95 \% \mathrm{Cl}=1.66-3.98, p<0.0001]$ followed by the presence of DM without HTN [HR 2.27, 95\% Cl=1.38-3.71, $p=0.001]$ (compared to those with neither).

Conclusion: $\mathrm{DM}$ is the strongest predictor of incident $\mathrm{HF}$, compared to other traditional risk factors, in Ethiopian patients with IHD. Those with both DM and HTN are at the highest risk.

Keywords: Ischemic heart disease, Heart failure, Incidence, Diabetes mellitus, Retrospective cohort study

\section{Background}

Ethiopia, with a population of close to 100 million and the second in population from Africa, is experiencing swift changes in the health and disease of its population like many of the rapidly developing countries in Africa. These changes are accompanied or driven by

\footnotetext{
* Correspondence: drsenbetag@yahoo.com

${ }^{1}$ Division of Cardiology, Department of Internal Medicine, School of

Medicine, College of Health Sciences, Addis Ababa University, Box 28287, /1000 Addis Ababa, Ethiopia

Full list of author information is available at the end of the article
}

socioeconomic development, industrialization, and urbanization [1]. One of these is the changing trend in the underlying causes of cardiovascular disease and heart failure (HF). Ischemic heart disease (IHD), one of the underlying causes of HF, is increasing in prevalence in Sub-Saharan Africa [2].

In Sub-Saharan Africa, IHD was previously considered rare, but George A. Mensah reported in 2008 that it ranks 8th among the leading causes of death in adults in the region [2]. Moreover, the prevalence of IHD and

(c) The Author(s). 2020 Open Access This article is licensed under a Creative Commons Attribution 4.0 International License, which permits use, sharing, adaptation, distribution and reproduction in any medium or format, as long as you give appropriate credit to the original author(s) and the source, provide a link to the Creative Commons licence, and indicate if changes were made. The images or other third party material in this article are included in the article's Creative Commons licence, unless indicated otherwise in a credit line to the material. If material is not included in the article's Creative Commons licence and your intended use is not permitted by statutory regulation or exceeds the permitted use, you will need to obtain permission directly from the copyright holder. To view a copy of this licence, visit http://creativecommons.org/licenses/by/4.0/ The Creative Commons Public Domain Dedication waiver (http://creativecommons.org/publicdomain/zero/1.0/) applies to the data made available in this article, unless otherwise stated in a credit line to the data. 
associated morbidities thought to be increasing because of the rising adverse behavioral and lifestyle changes that are associated with the rising urbanization and epidemiologic transition. In Ethiopia, the proportion of IHD has dramatically increased from 88 to 960 per 100,000 patients with cardiovascular disease over the last 30 years [3-6].

Diabetes [7], cigarette smoking [8], dyslipidemia [9], and hypertension (HTN) [10] have been established as independent risk factors for IHD in broad epidemiological researches. Older age, family history of early heart disease, race, obesity, lack of physical activity, metabolic syndrome, mental stress, and depression are the other established risk factors for IHD. However, most cardiovascular diseases (CVDs) can be prevented by addressing these risk factors [11].

Diabetes Mellitus (DM) is a major contributor to the various cardiac disorders, including left ventricular hypertrophy and reduced systolic and diastolic function. According to the 2015 International Diabetes Federation, the prevalence of DM in Ethiopian adults is 5.2\% [12]. The World Health Organization's report on trends in the prevalence of diabetes in Ethiopia has indicated that the prevalence of DM has been increasing over the past years [13].

The risk of adverse events in diabetic patients increases after the onset of myocardial infarction (MI). DM was also shown to be an independent risk factor for heart failure in many hospital-based and population-based cardiovascular studies including the Framingham Heart Study [7, 14]. Compared to nondiabetic patients, the risk of HF was found to be twofold and five-fold higher in diabetic men and women, respectively [14]. Even though mechanisms of HF in DM have not been well explained, the possible mechanisms are through causing diabetic cardiomyopathy [15], IHD [16] and effect on the heart of insufficient utilization of energy [17] and fatty acid metabolism [18]. This can indicate that intense glycaemic control reduces the incidence of HF in addition to reducing cardiovascular mortality.

Etiologies and clinical characteristics of HF were studied in Sub-Saharan Africa even though there are no population studies that provide evidence on its incidence

Table 1 Baseline socio-demographic characteristics of patients with diabetic and non-diabetic IHD patients

\begin{tabular}{|c|c|c|c|c|}
\hline \multirow[t]{2}{*}{ Variables } & \multirow{2}{*}{$\begin{array}{l}\text { All } \\
\text { patients } \\
(n=306)\end{array}$} & \multicolumn{2}{|l|}{$\mathrm{DM}$} & \multirow{2}{*}{$\begin{array}{l}P \text { - } \\
\text { value }\end{array}$} \\
\hline & & Yes $(n=96,31.4 \%)$ & No $(n=210,68.6 \%)$ & \\
\hline \multicolumn{5}{|l|}{ Baseline age (years) } \\
\hline 45 and less $(n, \%)$ & $59(19.3)$ & $21(21.9)$ & $38(18.1)$ & 1.00 \\
\hline $46-55(n, \%)$ & $96(31.4)$ & $26(27.1)$ & $70(33.3)$ & 0.26 \\
\hline $56-65$ & $88(28.8)$ & $27(28.1)$ & $61(29.0)$ & 0.53 \\
\hline 66 and above & $63(20.6)$ & $22(22.9)$ & $41(19.5)$ & 0.94 \\
\hline Mean $( \pm S D)$ age & $56.8(11.6)$ & $56.8(12.3)$ & $56.7(11.3)$ & 0.88 \\
\hline \multicolumn{5}{|l|}{ Sex } \\
\hline Male (\%) & $211(69.0)$ & $73(76.0)$ & $138(65.7)$ & 0.07 \\
\hline Female (\%) & $95(31.0)$ & $23(24.0)$ & $72(34.3$ & 1.00 \\
\hline \multicolumn{5}{|l|}{ Residence } \\
\hline Addis Ababa (\%) & $221(82.2)$ & $69(83.1)$ & $152(81.7)$ & 0.78 \\
\hline Outside Addis Ababa (\%) & $48(17.8)$ & $14(16.9)$ & $34(18.3)$ & 1.00 \\
\hline \multicolumn{5}{|l|}{ Smoking status } \\
\hline Never smoked (\%) & $258(84.3)$ & $77(80.2)$ & $181(86.2)$ & 1.00 \\
\hline Ever/Current smoker (\%) & $48(15.7)$ & 19 (19.8) & $29(13.8)$ & 0.18 \\
\hline \multicolumn{5}{|l|}{ Admission to hospital (\%) } \\
\hline Yes (\%) & $80(26.1)$ & $26(27.1)$ & $54(25.7)$ & 0.9 \\
\hline No (\%) & $226(73.9)$ & $70(72.9)$ & $156(74.3$ & 1.00 \\
\hline \multicolumn{5}{|c|}{ Number of hospital admissions } \\
\hline None (\%) & $229(74.8)$ & $72(75.0)$ & $157(74.8)$ & 1.00 \\
\hline Once (\%) & $64(20.9)$ & $19(19.8)$ & $45(21.4)$ & 0.79 \\
\hline Two or more (\%) & $13(4.2)$ & $5(5.2)$ & $8(3.8)$ & 0.60 \\
\hline
\end{tabular}


Table 2 Clinical and laboratory characteristics of patients with diabetic and non-diabetic IHD

\begin{tabular}{|c|c|c|c|c|}
\hline \multirow[t]{2}{*}{ Variables } & \multirow{2}{*}{$\begin{array}{l}\text { All patients }(n= \\
306)\end{array}$} & \multicolumn{2}{|l|}{ DM } & \multirow[t]{2}{*}{$P$-value* } \\
\hline & & Yes $(n=96,31.4 \%)$ & No $(n=210,68.6 \%)$ & \\
\hline \multicolumn{5}{|l|}{ Heart Failure } \\
\hline Yes & $196(64.1)$ & $70(72.9)$ & $126(60.0)$ & 0.029 \\
\hline No & $110(35.9)$ & $26(27.1)$ & $84(40.0)$ & 1.00 \\
\hline \multicolumn{5}{|l|}{ Corombidities } \\
\hline Yes & $168(54.9)$ & $61(63.5)$ & $107(51.0)$ & 0.04 \\
\hline No & $138(45.1)$ & $35(36.5)$ & $103(49.0)$ & 1.00 \\
\hline \multicolumn{5}{|l|}{ Type of Comorbidities } \\
\hline HTN & $144(47.1)$ & $53(55.2)$ & $91(43.3)$ & 0.07 \\
\hline Dyslipidemia at baseline & $48(15.7)$ & $25(26.0)$ & $23(11.0)$ & 0.001 \\
\hline Cerebrovascular accident & $15(4.9)$ & $1(1.0)$ & $14(6.7)$ & 0.06 \\
\hline Peripheral arterial disease & $3(1.0)$ & $1(1.0)$ & $2(1.0)$ & 1.0 \\
\hline \multicolumn{5}{|l|}{ Clinical status } \\
\hline NYHA class 3-4 HF (\%) & $85(27.8)$ & $40(41.7)$ & $45(21.4)$ & $<0.0001$ \\
\hline SBP (mmHg)-baseline & $129.38+/-19.20$ & $132.20+/-22.71$ & $128.15+/-17.34$ & 0.14 \\
\hline DBP (mmHg)-baseline & $80.25+/-9.68$ & $80.77+/-9.76$ & $80.02+/-9.65$ & 0.55 \\
\hline \multicolumn{5}{|l|}{ Laboratory Data mean or n (\%) } \\
\hline LVEF & $46.3+/-13.4$ & $44.7+/-12.3$ & $47.1+/-13.8$ & 0.2 \\
\hline LVDd (mm) & $51.2+/-10.3$ & $51.8+/-9.3$ & $50.9+/-10.8$ & 0.57 \\
\hline $\mathrm{LAD}(\mathrm{mm})$ & $36.7+/-6.8$ & $37.0+/-6.6$ & $36.6+/-6.9$ & 0.98 \\
\hline Hemoglobin (g/dl) & $14.4+/-2.0$ & $14.6+/-1.7$ & $14.3+/-2.1$ & 0.30 \\
\hline WBC count (mm3) & $7943.9+/-2848.3$ & $8318.7+/-2561$ & $7772.1+/-2962.6$ & 0.18 \\
\hline Nephropathy (\%) & $103(33.7)$ & $34(35.4)$ & $69(32.9)$ & 0.7 \\
\hline \multicolumn{5}{|l|}{ Medications (\%) } \\
\hline Aspirin & $281(91.8)$ & $92(95.8)$ & $189(90.0)$ & 0.1 \\
\hline Statins & $261(85.3)$ & 87 (90.6) & $174(82.9)$ & 0.1 \\
\hline B-blockers & $254(83.0)$ & $83(86.5)$ & $171(81.4)$ & 0.4 \\
\hline RAS inhibitors & $252(82.4)$ & $81(84.4)$ & $171(81.4)$ & 0.6 \\
\hline Loop diuretics & $121(39.5)$ & 38 (39.6) & $83(39.5)$ & 1.0 \\
\hline Aldosterone antagonists & $78(25.5)$ & $21(21.9)$ & $57(27.1)$ & 0.4 \\
\hline Clopidogrel & $32(10.5)$ & $11(11.5)$ & $21(10.0)$ & 0.9 \\
\hline Digoxin & $27(8.8)$ & $4(4.2)$ & $23(11.0)$ & 0.09 \\
\hline Hydrochlorthiazide & $42(13.7)$ & $16(16.7)$ & $26(12.4)$ & 0.4 \\
\hline Calcium channel blocker & $34(11.1)$ & $14(14.6)$ & $20(9.5)$ & 0.3 \\
\hline Use of antidiabetic medication & $96(31.4)$ & $96(100)$ & - & \\
\hline Insulin & $24(7.8)$ & $24(100)$ & - & \\
\hline Metformin & $85(14.1)$ & $85(100)$ & - & \\
\hline Sulfonilureas & $12(3.9)$ & $12(100)$ & - & \\
\hline
\end{tabular}

* For Chi-square test for independence, $\mathrm{p}$-value of Yates Continuity Correction was taken

or prevalence [19]. In Ethiopian setting where there is a change in the trend of underlying causes of heart failure with a dramatically increasing prevalence of IHD and a continually increasing prevalence of DM $[5,6]$, it is imperative to study the effect of DM on the incidence of
HF in patients with IHD. Besides, evidence regarding the incremental impact of DM on HF in patients with IHD is scarce. The primary aim of this study was thus to test the hypothesis of whether DM has an incremental risk of incident HF in patients with IHD. 


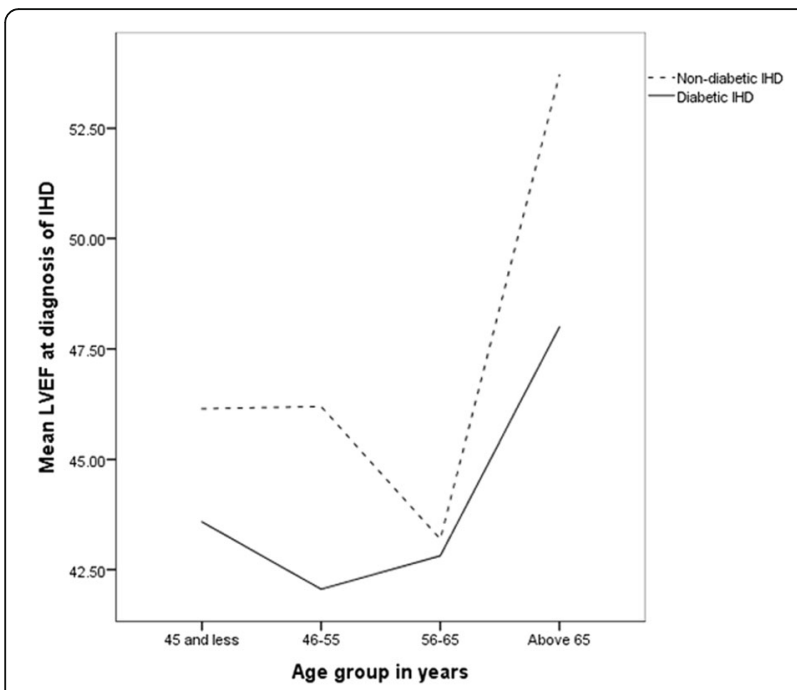

Fig. 1 Line graph of the left ventricular ejection fraction of diabetic and non-diabetic IHD patients across four age groups

\section{Methods}

\section{Study design and clinical setting}

This is a retrospective cohort study done at Tikur Anbessa Specialized Hospital (TASH) in Addis Ababa, Ethiopia to assess the incremental effect of DM on incident HF in patients with IHD.TASH is an institution where specialized clinical services are rendered to the whole nation. TASH offers general internal medicine and cardiology services together with other services. The adult cardiology clinic at TASH provides specialized cardiac care to patients referred from hospitals and health institutions from all regions of the country.

The study population was recruited until November 30,2015 , and each case was followed up for 24 months. The incidence of new cases with HF was recorded among patients with and without DM. Patients with IHD, DM or HF were identified based on the treating Physician's final diagnosis. Those with IHD and diabetes were taken as exposed and those with IHD but no diabetes were taken as unexposed.

\section{Study population}

The target population consists of adult patients (age of 18 years and above) with IHD. We followed our cohort of IHD patients to measure their outcomes. The primary outcome of interest was incident HF. Study participants were considered exposed if the duration of DM before a diagnosis of HF was three or more months so that the diagnosis of DM is established. Patients diagnosed with IHD and with no history of HF at baseline were included. Patients with a history of HF or who were using furosemide at baseline were excluded. There were a total of 306 patients with IHD who fulfilled the inclusion criteria, 96 of them diabetic and 210 non-diabetic. The calculated power of the study to detect difference was 93.7\%.

\section{Operational definitions}

IHD was defined based on information from patient records where the attending physician (Cardiologist) made the diagnosis. Diabetes Mellitus was defined as a confirmed history of this diagnosis or the prescription of glucose-lowering drugs based on information from patient records. HF was defined as the presence of Physician documented diagnosis of $\mathrm{HF}$ and/or prescription of a loop diuretic. Hypertension was defined based on physician-registered diagnosis on the medical record. Patients were diagnosed to have hypertension if systolic blood pressure $\geq 140 \mathrm{mmHg}$, diastolic blood pressure $\geq$ $90 \mathrm{mmHg}$, or taking anti-hypertensive medications.

Smoking status was classified as current smokers or non-smokers based on reports in the history record or risk factors of IHD listed on the medical record. Anemia diagnosis was made if the hemoglobin level was $<12 \mathrm{~g} /$ dL. A nephropathy diagnosis was made if there was a trace or above proteinuria.

\section{Data collection}

Data were collected by trained nurses from the medical records of the study participants using a pre-tested structured questionnaire. A total of 306 medical records of patients newly diagnosed with IHD until November 30,2015 , were identified to determine the incidence of HF in IHD with or without DM. Subjects were followed from the date of enrolment until they were diagnosed to have HF or November 30, 2017 (study exit date). Individuals with established HF before the date of enrolment were excluded. Those who died or lost to follow up before the study exit date were censored during analysis.

IHD patients diagnosed with DM anytime during the study period were labeled as exposed and those with no DM, until less than 3 months before the study exit were labeled as unexposed.

The questionnaire contained demographic variables (age, sex), smoking, diagnosis and date of diagnosis of IHD, diagnosis, and date of diagnosis of DM, diagnosis, and date of diagnosis of HF, diagnosis, and functional classification of HF based on New York Heart Association (NYHA) classification, blood pressure level, full blood count, fasting blood glucose, lipid profile, urea, and plasma creatinine, and electrolytes. Data on comorbidities (anemia, dyslipidemia, HTN, and chronic kidney disease), medications, and hospital admission were collected. Information from resting 12-lead electrocardiography and transthoracic echocardiography were collected. In the case of participants with missing information, the available data was taken for analysis. 
Table 3 Factors associated with onset of HF among IHD patients in bivariate analysis

\begin{tabular}{|c|c|c|c|c|}
\hline \multirow[t]{2}{*}{ Variables } & \multicolumn{2}{|l|}{ IHD patients with HF } & \multirow[t]{2}{*}{$\operatorname{COR}(95 \% \mathrm{Cl})^{*}$} & \multirow{2}{*}{$\begin{array}{l}P \text { - } \\
\text { value }\end{array}$} \\
\hline & Yes $(n=196,64.1 \%)$ & No $(n=110,35.9 \%)$ & & \\
\hline \multicolumn{5}{|l|}{ Baseline age (years) } \\
\hline 45 and less $(n, \%)$ & $29(49.2)$ & $30(50.8)$ & 1.00 & \\
\hline $46-55(n, \%)$ & $62(64.6)$ & $34(35.4)$ & $1.89(0.98-3.65)$ & 0.06 \\
\hline $56-65$ & $61(69.3)$ & $27(30.7)$ & $2.34(1.18-4.63)$ & 0.02 \\
\hline 66 and above & $44(69.8)$ & $19(30.2)$ & $2.40(1.14-5.03)$ & 0.02 \\
\hline Mean $( \pm S D)$ age & $57.89(11.1)$ & $54.48(12.2)$ & $\mathrm{t}(304)=-2.48$, two tailed & 0.01 \\
\hline \multicolumn{5}{|l|}{ Sex } \\
\hline Male (\%) & $124(58.8)$ & $87(41.2)$ & 1.00 & \\
\hline Female (\%) & $72(75.8)$ & $23(24.2)$ & $2.20(1.28-3.78)$ & 0.005 \\
\hline \multicolumn{5}{|l|}{ Smoking status } \\
\hline Never smoked (\%) & $167(64.7)$ & $91(35.3)$ & 1.00 & \\
\hline Ever/Current smoker (\%) & $29(60.4)$ & 19 (39.6) & $0.83(0.44-1.57)$ & 0.57 \\
\hline \multicolumn{5}{|l|}{ Admission to hospital (\%) } \\
\hline Yes (\%) & $55(68.8)$ & $25(31.3)$ & $1.33(0.77-2.29)$ & 0.31 \\
\hline No (\%) & $141(62.4)$ & 85 (37.6) & 1.00 & \\
\hline \multicolumn{5}{|l|}{ DM } \\
\hline Yes (\%) & $70(72.9)$ & $26(27.1)$ & $1.80(1.06-3.04)$ & 0.03 \\
\hline No (\%) & $126(60.0)$ & $84(40.0)$ & 1.00 & \\
\hline \multicolumn{5}{|l|}{ HTN } \\
\hline Yes (\%) & $98(68.1)$ & $46(31.9)$ & $1.39(0.87-2.23)$ & 0.17 \\
\hline No (\%) & $98(60.5)$ & $64(39.5)$ & 1.00 & \\
\hline \multicolumn{5}{|l|}{ LVEF $<40 \%$} \\
\hline Yes (\%) & $57(76.0)$ & $18(24.0)$ & $1.88(1.01-3.51)$ & 0.047 \\
\hline No (\%) & $96(62.7)$ & $57(37.3)$ & 1.00 & \\
\hline LA & $37.43(6.76)$ & $34.60(6.39)$ & $\mathrm{t}(196)=-2.87$, two tailed & 0.005 \\
\hline \multicolumn{5}{|l|}{ Nephropathy [1] } \\
\hline Yes (\%) & $62(60.2)$ & $41(39.8)$ & $0.78(0.48-1.27)$ & 0.32 \\
\hline No (\%) & $134(66.0)$ & $69(34.0)$ & 1.00 & \\
\hline \multicolumn{5}{|l|}{ Dyslipidemia } \\
\hline Yes (\%) & $31(64.6)$ & $17(35.4)$ & $1.03(0.54-1.96)$ & 0.93 \\
\hline No (\%) & $165(64.0)$ & $93(36.0)$ & 1.00 & \\
\hline
\end{tabular}

*COR Crude Odds Ratio; Cl Confidence Interval

\section{Data management and analysis}

Data were entered into an electronic database using SPSS version 23, and then data analysis was done. The proportion of HF in diabetic IHD patients and nondiabetic IHD was calculated. Comparisons were done within age groups. Categorical variables were reported as frequencies (\%) and continuous variables reported using mean (standard deviation) or median (inter-quartile range). Pearson's Chi-square test for independence (with Yates Continuity Correction) was used to compare the difference in proportions of HF between diabetic and non-diabetic IHD patients.
In patients diagnosed to have HF further analysis was done to compare differences between patients with diabetic IHD and non-diabetic IHD. The independentsample t-test was used to compare the difference between the two groups in ejection fraction (LVEF), left atrial (LA) size, left ventricular diastolic dimension and demographic variables like age. Multivariable logistic regression analysis was conducted to estimate the effect of DM on HF adjusted for potential confounding variables such as age, sex, hypertension, smoking, dyslipidemia, nephropathy, LVEF, and LA size. The Kaplan-Meier procedure was used to estimate the survival curves and Cox 
Table 4 Factors associated with onset of HF among IHD patients in multivariate analysis

\begin{tabular}{|c|c|c|c|c|}
\hline \multirow[t]{2}{*}{ Variables } & \multicolumn{2}{|l|}{ IHD patients with HF } & \multirow[t]{2}{*}{$\operatorname{AOR}(95 \% \mathrm{Cl})^{*}$} & \multirow{2}{*}{$\begin{array}{l}\boldsymbol{P} \text { - } \\
\text { value }\end{array}$} \\
\hline & Yes $(n=196,64.1 \%)$ & No $(n=110,35.9 \%)$ & & \\
\hline \multicolumn{5}{|l|}{ Baseline age (years) } \\
\hline 45 and less $(n, \%)$ & $29(49.2)$ & $30(50.8)$ & 1.00 & \\
\hline $46-55(n, \%)$ & $62(64.6)$ & $34(35.4)$ & $2.19(0.90-5.30)$ & 0.08 \\
\hline $56-65$ & $61(69.3)$ & $27(30.7)$ & $2.91(1.16-7.27)$ & 0.02 \\
\hline 66 and above & $44(69.8)$ & $19(30.2)$ & $4.07(1.40-11.83)$ & 0.01 \\
\hline Overall & $57.89(11.1)$ & $54.48(12.2)$ & & 0.04 \\
\hline \multicolumn{5}{|l|}{ Sex } \\
\hline Male (\%) & $124(58.8)$ & $87(41.2)$ & 1.00 & \\
\hline Female (\%) & $72(75.8)$ & $23(24.2)$ & $2.64(1.25-5.60)$ & 0.01 \\
\hline \multicolumn{5}{|l|}{$\mathrm{DM}$} \\
\hline Yes (\%) & $70(72.9)$ & $26(27.1)$ & $2.34(1.13-4.85)$ & 0.02 \\
\hline No (\%) & $126(60.0)$ & $84(40.0)$ & 1.00 & \\
\hline \multicolumn{5}{|l|}{ HTN } \\
\hline Yes (\%) & $98(68.1)$ & 46 (31.9) & $1.15(0.58-2.30)$ & 0.69 \\
\hline No (\%) & $98(60.5)$ & 64 (39.5) & 1.00 & \\
\hline \multicolumn{5}{|l|}{ LVEF $<40 \%$} \\
\hline Yes (\%) & $57(76.0)$ & $18(24.0)$ & $1.79(0.87-3.69)$ & 0.11 \\
\hline No (\%) & $96(62.7)$ & $57(37.3)$ & 1.00 & \\
\hline LA & $37.43(6.76)$ & $34.6(6.39)$ & $1.08(1.02-1.14)$ & 0.004 \\
\hline
\end{tabular}

${ }^{*}$ AOR Adjusted Odds Ratio; CI Confidence Interval; DM DM diagnosis; HTN HTN; LVEF LV ejection fraction; LA left atrium

Table 5 Cox Hazard Models for incident HF

\begin{tabular}{|c|c|c|c|}
\hline \multirow[t]{2}{*}{ HR categorises } & \multicolumn{3}{|c|}{ All patients $(n=174)$} \\
\hline & $\mathrm{HR}$ & $95 \% \mathrm{Cl}$ & $P$-value \\
\hline \multicolumn{4}{|l|}{ Univariate } \\
\hline Non-diabetic IHD & 1.00 & & \\
\hline Diabetic IHD & 2.43 & $1.73-3.41$ & $<0.0001$ \\
\hline \multicolumn{4}{|l|}{ Multivariate } \\
\hline Non-diabetic IHD & 1.00 & & \\
\hline Diabetic IHD & 2.04 & $1.32-3.14$ & 0.001 \\
\hline No HTN & 1.00 & & \\
\hline HTN & 1.17 & $0.72-1.90$ & 0.52 \\
\hline Female & 1.00 & & \\
\hline Male & 1.17 & $0.77-1.77$ & 0.46 \\
\hline Age 45 years \& less & 1.00 & & \\
\hline $46-55$ years & 0.89 & $0.50-1.60$ & 0.70 \\
\hline $56-65$ years & 1.12 & $0.60-2.09$ & 0.73 \\
\hline 66 and above & 1.04 & $0.53-2.05$ & 0.92 \\
\hline LVEF 50\% \& above & 1.00 & & \\
\hline LVEF 40-49\% & 1.04 & $0.62-1.75$ & 0.88 \\
\hline LVEF $<40 \%$ & 1.41 & $0.89-2.30$ & 0.16 \\
\hline Normal LA & 1.00 & & \\
\hline Dilated LA & 1.48 & $0.99-2.22$ & 0.06 \\
\hline
\end{tabular}

regression analysis was used to calculate the hazard ratios for predictors of HF. In cases of missing data, the 'Exclude cases pairwise' option was used during analysis. A 5\% significance level was adopted for all tests and all tests were 2 -sided.

\section{Ethical considerations}

Ethical clearance was obtained from the Institutional Review Board of the College of Health Sciences, Addis Ababa University. Informed consent was waived by theIRB due to the retrospective nature of the study with no more than minimal risk. Eligible medical records were evaluated further for inclusion and exclusion criteria.

\section{Results}

Baseline characteristics and clinical presentation

Baseline characteristics of 306 patients with IHD (96 diabetic and 210 non-diabetic) who were retrospectively followed till November 30, 2017, is shown in Table 1. The mean age was 56.8 years and male patients accounted for $69 \%$. The prevalence of DM and HTN were 31.4 and $47.1 \%$, respectively.

As shown in Table 2, during the 24 months follow-up, the endpoint (HF) occurred in 196 patients (64.1\%). The proportion of DM was higher in male patients. The 
proportion of admission to hospital, smoking, HTN, dyslipidemia, functional class III-IV HF and nephropathy were higher in the diabetic IHD patients. The diabetic IHD patients also had lower LVEF, bigger LV enddiastolic dimension and bigger left atrial dimension. Cerebrovascular accidents and the use of digoxin were found to be higher in the non-diabetic IHD. As compared to the non-diabetic IHD patient, patients with diabetic IHD had significantly higher incidence of HF ( $p=$ $0.029)$,higher prevalence of dyslipidemia $(p=0.001)$, and higher prevalence of functional class III- IV HF $(p=<$ 0.0001).

Diabetic IHD patients appear to have a lower level of left ventricular ejection fraction (LVEF) than the nondiabetic IHD patients (Fig. 1). In both diabetic and nondiabetic IHD patient groups, LVEF appears to be higher in older patients.

\section{Risk factors for HF in patients with IHD}

To assess the impact of the number of factors on the likelihood that patients develop new-onset HF we performed direct logistic regression. In bivariate analysis, as shown in Table 3, age, female sex, DM, LV ejection fraction less than $40 \%$ and bigger left atrial diameter had a significant association with incident HF. Age groups 5665 and 66 and above had a significantly higher incidence of HF as compared to the younger age group.

The multivariate model contained six independent variables (sex, age, DM, HTN, left ventricular ejection fraction and left atrial size). The full model containing all predictors was statistically significant, $\mathrm{X} 2(8, N=$ 306) $=28.9, p<.0001$, indicating that the model was able to distinguish between those with and without newonset HF. As shown in Table 4, four of the independent variables made a unique statistically significant contribution to the model (sex, age, DM and left atrial size). The strongest predictors of new-onset HF were sex and $\mathrm{DM}$, recording an odds ratio of 2.6 and 2.3 respectively. This indicated that female patients and those who had DM were about 2.5 times more likely to develop newonset HF than male patients and those who did not have $\mathrm{DM}$, respectively, controlling for all other factors in the model. Moreover, patients with new-onset HF were older and had a larger left atrial size.

Table 5 shows the results of Cox proportional hazard regression models for predictors of incident HF. We find that the covariates contribute significantly to explaining the new-onset HF [X2 [9] $=21.69, p=0.01] .\left[\mathrm{X}^{2}[10]=\right.$ 24.12, $p=0.07]$.

On univariate analysis, DM was associated with a worse prognosis. On multivariate analysis, at the 5\% level, only DM is shown to significantly affect the hazard function after adjusting for the effects of age, sex, HTN, LV ejection fraction and LA size. As compared with the non-diabetic patients, diabetic patients had a 2.04-fold higher risk for the incident HF $(P=0.001)$. The results show that with an increase in diabetes by 1 unit, there is an increase in the hazard function for new-onset HF by $104.0 \%$ (95\% CI from 32.0 to $214.0 \%$ ).

\section{Discussion}

In this hospital-based study, we found that in patients with established IHD, the presence of diabetes increased the incidence of HF by more than two-fold when compared with the non-diabetic counterparts. IHD was reported to be the most important cause of $\operatorname{HF}[20,21]$. In this study, the presence of diabetes increased the incidence of HF synergistically with IHD.

The finding of increased incident HF among patients with diabetic IHD in our study is consistent with previous reports. In patients with no HTN or IHD, diabetes was found to be an independent risk factor for HF [22]. The mechanisms of HF in diabetes have not been well explained. However, the following are the possible suggested mechanisms. Diabetes is a risk factor for atherosclerosis which results in IHD [16] and thus further increasing the risk of HF [22]. Diabetes also causes "diabetic cardiomyopathy" which leads to HF independent of other risk factors [15]. The possible mechanisms of diabetic cardiomyopathy include hyperinsulinemia [23], endothelial dysfunction [24], metabolic disturbance [17], changes in calcium homeostasis [25] and autonomic nervous system dysregulation [26]. The other effect of diabetes on the heart include insufficient utilization of energy [17] and fatty acid metabolism [18] subsequently leading to HF. Poor glycemic control is related to an increased risk of $\mathrm{HF}$. With every $1 \%$ increase in hemoglobin A1c, an indicator for glycemic control, the risk of $\mathrm{HF}$ is increased by $8 \%$ [27]. This suggests that if glucose control is good, the risk of HF and cardiovascular mortality can be reduced [28].

The other risk factors at baseline that were also associated with an increased incidence of HF were female sex, older age and larger left atrial size. In a study done on patients with IHD, there was no factor, other than diabetes, that had a significant association with incident $\mathrm{HF}$, except for a marginally significant variation in alcohol consumption [29] but they did not include echocardiography parameters in their analysis.

There are certain limitations to this study. Information bias is the major limitation in our retrospective cohort study as some of the records were missing data. Data on LVEF and the length of treatment duration were not complete and thus we did not do analyses on these variables. A 24-month long follow up for incident HF as an endpoint is also probably short. IHD was defined based on information from patient medical records where the 
attending physician (Cardiologist) made the diagnosis. There were no data on coronary angiography which is, therefore, another limitation of this study. The other possible limitation is that the data was collected from a selected hospital, although it is the largest referral center in the country. This may affect the generalizability of the finding to the whole Ethiopian population.

We took a complete study population until the desired sample size was achieved. This may minimize the possibility of selection bias. We also recommend a prospective study with a larger sample size.

\section{Conclusion}

Our study provides strong evidence for diabetes as an independent risk factor for new-onset HF, compared to other traditional risk factors, in Ethiopian patients with IHD. Those with both DM and HTN are at the highest risk. This study has also shown that the time to incident HF in patients with diabetic IHD is shorter compared to the non-diabetic IHD patients. Strong efforts should be made to develop strategies to prevent HF in adults with diabetic IHD. Optimizing glycemic control in diabetic IHD patients should also be a fundamental step. DM is the strongest predictor of incident $\mathrm{HF}$, compared to other traditional risk factors, in Ethiopian patients with IHD. Those with both DM and HTN are at the highest risk.

\section{Abbreviations}

HF: Heart failure; IHD: Ischemic heart disease; DM: Diabetes mellitus; HTN: Hypertension; TASH: TikurAnbessa specialized hospital; NYHA: New York heart association; LVEF: Left ventricular ejection fraction; LA: Left atrium; COR: Crude odds ratio; AOR: Adjusted odds ratio; Cl: Confidence interval; MEPI: Medical education partnership initiative-Ethiopia

\section{Acknowledgments}

We are grateful to the data collectors who participated in this project.

\section{Authors' contributions}

SGA contributed to the conception, design, data collection, analysis, writing, and review of the manuscript. WD contributed to the conception, design, analysis, and review of the manuscript. AS contributed to the conception, design, analysis, and review of the manuscript. All authors have read and approved the manuscript and have approved its submission to BMC Cardiovascular Disorders.

\section{Funding}

This work was supported by the Medical Education Partnership InitiativeEthiopia (MEPI). The funding body had no role in the design of the study, data collection, analysis, interpretation of data, or in writing the manuscript.

\section{Availability of data and materials}

The datasets used and/or analyzed during the current study are available from the corresponding author on reasonable request.

\section{Ethics approval and consent to participate}

Ethical clearance was obtained from the Institutional Review Board of the College of Health Sciences, Addis Ababa University. Informed consent was waived by the IRB due to the retrospective nature of the study with no more than minimal risk. Eligible medical records were evaluated further for inclusion and exclusion criteria.

\section{Consent for publication}

NA.

\section{Competing interests}

The authors declare that they have no competing interests.

\section{Author details}

'Division of Cardiology, Department of Internal Medicine, School of Medicine, College of Health Sciences, Addis Ababa University, Box 28287, /1000 Addis Ababa, Ethiopia. ²Department of Preventive Medicine, School of Public Health, College of Health Sciences, Addis Ababa University, Addis Ababa, Ethiopia. ${ }^{3}$ Department of Epidemiology, Rollins School of Public Health, Emory University, Atlanta, USA. ${ }^{4}$ Division of Cardiology, Department of Medicine, Emory University School of Medicine, Atlanta, USA.

Received: 30 July 2019 Accepted: 1 April 2020

Published online: 19 April 2020

\section{References}

1. National Research Council Committee on P. In: Gribble JN, Preston SH, editors. The Epidemiological Transition: Policy and Planning Implications for Developing Countries: Workshop Proceedings. Washington: National Academies Press (US): 1993.

2. Mensah GA. Ischaemic heart disease in Africa. Heart. 2008;94(7):836-43 PubMed PMID: 18552223. Epub 2008/06/17. eng.

3. Hodes RM. Pattern of heart disease in Ethiopia as seen in a cardiology referral clinic. Cardiology. 1988;75:458-64.

4. Maru M. The changing pattern of cardiovascular diseases in Ethiopia. East Afr Med J. 1993;70:772-6.

5. Abdissa SG, Oli K, Feleke Y, Goshu DY, Begna DM, Tafese A. Spectrum of cardiovascular diseases among Ethiopian patients at Tikur Anbessa Specialized University teaching hospital. Addis Ababa Ethiop Med J. 2014; 52(1):9-17.

6. Yadeta D, Guteta S, Alemayehu B, et al. Spectrum of cardiovascular diseases in six main referral hospitals of Ethiopia. Heart Asia. 2017;9:e010829. https:// doi.org/10.1136/heartasia-2016-010829.

7. Kannel WB, McGee DL. Diabetes and cardiovascular disease. The Framingham study. Jama. 1979;241(19):2035-8 PubMed PMID: 430798. Epub 1979/05/11. eng.

8. Nyboe J, Jensen G, Appleyard M, Schnohr P. Smoking and the risk of first acute myocardial infarction. Am Heart J. 1991;122(2):438-47 PubMed PMID: 1858623. Epub 1991/08/01. eng.

9. Stamler J, Vaccaro O, Neaton JD, Wentworth D. Diabetes, other risk factors, and 12-yr cardiovascular mortality for men screened in the multiple risk factor intervention trial. Diabetes Care. 1993;16(2):434-44 PubMed PMID: 8432214. Epub 1993/02/01. eng.

10. MacMahon S, Peto R, Cutler J, Collins R, Sorlie P, Neaton J, et al. Blood pressure, stroke, and coronary heart disease. Part 1, Prolonged differences in blood pressure: prospective observational studies corrected for the regression dilution bias. Lancet (London, England). 1990;335(8692):765-74 PubMed PMID: 1969518. Epub 1990/03/31. eng.

11. Collins R, Peto R, MacMahon S, Hebert P, Fiebach NH, Eberlein KA, et al. Blood pressure, stroke, and coronary heart disease. Part 2, Short-term reductions in blood pressure: overview of randomised drug trials in their epidemiological context. Lancet (London, England). 1990;335(8693):827-38 PubMed PMID: 1969567 Epub 1990/04/07. eng.

12. International Diabetes Federation. Prevalence of Diabetes in Ethiopian adults. Access date May 24, 2018 2015. Available from: https:/www.idf.org/ our-network/regions-members/africa/members/9-ethiopia.html.

13. World Health Organization. Trends in age-standardized prevalence of Diabetes. Available from: http://www.who.int/diabetes/country-profiles/eth_ en.pdf. Accessed on 08 Aug 2018.

14. Nichols GA, Gullion CM, Koro CE, Ephross SA, Brown JB. The incidence of congestive heart failure in type 2 diabetes: an update. Diabetes Care. 2004; 27(8):1879-84 PubMed PMID: 15277411. Epub 2004/07/28. eng.

15. Rubler S, Dlugash J, Yuceoglu YZ, Kumral T, Branwood AW, Grishman A. New type of cardiomyopathy associated with diabetic glomerulosclerosis. Am J Cardiol. 1972;30(6):595-602.

16. Haffner SM, Lehto S, Rönnemaa T, Pyörälä K, Laakso M. Mortality from coronary heart disease in subjects with type 2 diabetes and in nondiabetic 
subjects with and without prior myocardial infarction. N Engl J Med. 1998; 339(4):229-34 PubMed PMID: 9673301.

17. Knaapen P, Germans T, Knuuti J, Paulus WJ, Dijkmans PA, Allaart CP, et al. Myocardial energetics and efficiency. Curr Status Noninvasive Approach. 2007;115(7):918-27.

18. Hafstad AD, Solevåg GH, Severson DL, Larsen TS, Aasum E. Perfused hearts from type 2 diabetic (db/db) mice show metabolic responsiveness to insulin. Am J Phys Heart Circ Phys. 2006;290(5):H1763-H9 PubMed PMID: 16327015.

19. Makubi A, Hage C, Lwakatare J, Kisenge P, Makani J, Rydén L, et al. Contemporary aetiology, clinical characteristics and prognosis of adults with heart failure observed in a tertiary hospital in Tanzania: the prospective Tanzania Heart Failure (TaHeF) study. Heart (British Cardiac Society). 2014; 100(16):1235-41 PubMed PMID: PMC5555386.

20. Chen YT, Vaccarino V, Williams CS, Butler J, Berkman LF, Krumholz HM. Risk factors for heart failure in the elderly: a prospective community-based study. Am J Med. 1999;106(6):605-12 PubMed PMID: 10378616.

21. Kannel WB, Hjortland M, Castelli WP. Role of diabetes in congestive heart failure: the Framingham study. Am J Cardiol. 1974;34(1):29-34 PubMed PMID: 4835750

22. Wilson PWF, D'Agostino RB, Levy D, Belanger AM, Silbershatz H, Kannel WB. Prediction of coronary heart disease using risk factor categories. Circulation. 1998;97(18):1837-47.

23. Devereux RB, Roman MJ, Paranicas M, O'Grady MJ, Lee ET, Welty TK, et al. Impact of diabetes on cardiac structure and function: the strong heart study. Circulation. 2000;101(19):2271-6 PubMed PMID: 10811594.

24. Chou E, Suzuma I, Way K, Opland D, Clermont AC, Naruse K, et al. Decreased cardiac expression of vascular endothelial growth factor and its receptors in insulin-resistant and diabetic states. A Possible Explanation for Impaired Collateral Formation in Cardiac Tissue. Circulation. 2002;105(3):373-9.

25. Lacombe VA, Viatchenko-Karpinski S, Terentyev D, Sridhar A, Emani S, Bonagura JD, et al. Mechanisms of impaired calcium handling underlying subclinical diastolic dysfunction in diabetes. Am J Physiol Regul Integr Comp Physiol. 2007;293(5):R1787-97 PubMed PMID: 17761517. Pubmed Central PMCID: PMC2413069.

26. Fang ZY, Prins JB, Marwick TH. Diabetic cardiomyopathy: evidence, mechanisms, and therapeutic implications. Endocr Rev. 2004;25(4):543-67.

27. Iribarren C, Karter AJ, Go AS, Ferrara A, Liu JY, Sidney S, et al. Glycemic control and heart failure among adult patients with diabetes. Circulation. 2001;103(22):2668-73.

28. UK Prospective Diabetes Study (UKPDS) Group. Effect of intensive bloodglucose control with metformin on complications in overweight patients with type 2 diabetes (UKPDS 34). The Lancet. 1998;352(9131):854-65.

29. Patel N, Chen O, Donahue C, Wang B, Fang Y, Donnino R, et al. Impact of diabetes on heart failure incidence in adults with ischemic heart disease. $J$ Diabetes Complicat. 2017;31(11):1597-601 PubMed PMID: 28947278.

\section{Publisher's Note}

Springer Nature remains neutral with regard to jurisdictional claims in published maps and institutional affiliations.

Ready to submit your research? Choose BMC and benefit from:

- fast, convenient online submission

- thorough peer review by experienced researchers in your field

- rapid publication on acceptance

- support for research data, including large and complex data types

- gold Open Access which fosters wider collaboration and increased citations

- maximum visibility for your research: over $100 \mathrm{M}$ website views per year

At BMC, research is always in progress.

Learn more biomedcentral.com/submissions 